\section{Can I risk using public services? Perceived consequences of seeking help and health care among households living in poverty: qualitative study}

\author{
Krysia Canvin, Chris Jones, Anneli Marttila, Bo Burström, \\ Margaret Whitehead
}

Objectives: To improve understanding of how families living in adverse conditions perceive their encounters with public services and how past experiences influence current and future attempts to seek help.

Design: Qualitative interviews with adult members of households living in poverty in deprived areas, plus observations conducted in the surrounding neighbourhoods and service settings.

Participants: Purposive sample of 25 adults living in a deprived area, on welfare benefits.

Setting: Eight sites in disadvantaged areas in Merseyside, North Wales, London and Greater Manchester in 2004/05.

See end of article for authors' affiliations

Correspondence to: $M$ Whitehead, Division of Public Health, University of Liverpool, Whelan Building, Quadrangle, Brownlow Hill, Liverpool L69 3GB, UK; mmw@liverpool.ac.uk

Accepted 17 February 2007
Results: Participants generally perceived public services as a source of distrust and a potential risk to wellbeing. Encounters with a range of services were perceived as risky in terms of losing resources, being misunderstood or harshly judged, and carrying the ultimate threat of losing custody of their children. Participants perceived that they were subjected to increasing levels of surveillance, with fear of "being told on" by neighbours, in addition to service providers, adding to anxiety. Adverse consequences included avoiding child health and social services, anxiety and self-imposed isolation.

Conclusions: Approaching services was perceived as akin to taking a gamble that might or might not result in their needs being met. Faced with this "choice", participants employed strategies to minimise the risks that on the surface may appear risky to health. If public services are to succeed in providing support to disadvantaged families, greater efforts are needed to build trust and demonstrate understanding for the strategies these families use to maintain their well-being against formidable odds.
$\mathrm{T}$ he low uptake of preventative services in disadvantaged communities is a continuing challenge to public health. ${ }^{1-4}$ Families living in adverse conditions have high rates of illhealth and consequently are at greatest need of health and welfare services. ${ }^{15-7}$ Paradoxically, these families have the poorest access to curative and preventative services. ${ }^{8-10}$ Public health and primary care practitioners are involved in attempts to improve access to, and quality of, services in disadvantaged areas. National targets set for reducing inequalities in health and health care are couched in terms of "levelling up" - making faster improvements in the most disadvantaged areas relative to the rest of the population by 2010 . The primary care trusts that constitute the so-called "Spearhead" group, which cover the most disadvantaged populations, are being held to account by the Department of Health for the progress they are making on this front.

A new initiative on poverty and social exclusion announced by the prime minister of the UK aims to provide support to the most disadvantaged families and intervene at an early stage. ${ }^{11}$ Proposed interventions include an intensified health visitor programme, parenting classes and help with alcohol and drug abuse. ${ }^{12}$ These plans follow the introduction of electronic child indexes under the Children Act 2004, which were intended to improve children's access to universal and additional services and thus provide preventative, holistic services and early intervention for children in need. The context for the latest initiative is the growing focus on prevention of antisocial behaviour in later years and the view that "you can detect and predict the children and families likely to go wrong". ${ }^{11}$ These initiatives also reflect an intensification of surveillance in society in general over the past 15 years, ${ }^{13}$ but with a particular focus on and subsequent intervention for the poorest members of society. While the focus on helping disadvantaged families has been welcomed, leading policy analysts and practitioners have warned of the need for extreme sensitivity: the implementation of such measures could stigmatise and alienate the people they are trying to help and even impede service uptake. ${ }^{14}$ ${ }^{17}$ Against this background, our paper addresses some of the complexities and pitfalls encountered by health care providers in disadvantaged areas, but, crucially, it does so from the perspective of the disadvantaged households at whom these policies are aimed. Our study offers insights into their experiences of public services, seeking to understand what aspects of those encounters influence the intentions of disadvantaged households to seek support now and in the future.

\section{METHODS}

Grounded theory informed the design of this study. ${ }^{18}$ We sought a purposive sample of individuals with experience of material adversity (defined as living in a deprived area, on welfare benefits) (box 1) who could talk about using public services. We conducted field work in eight sites (sites $\mathrm{A}-\mathrm{H}$ ), providing a variety of geographical and service settings, and enabling us to avoid regional or service bias arising from any single context and thus enhancing the transferability of our findings (table 1). Potential participants were approached via non-statutory services. Most were introduced to the researcher by a professional, and most were invited to participate by the researcher. Very few were told about the study by other participants. No-one refused outright to participate, but four individuals who considered participating were not subsequently 


\begin{tabular}{ll}
\hline $\begin{array}{l}\text { Table } 1 \\
(\mathrm{n}=25)\end{array}$ & Characteristics of the interview sample \\
\hline Characteristics & Number of participants \\
\hline Male & 6 \\
Female & 19 \\
Parents & 21 \\
Not parents & 3 \\
Not known & 1 \\
Fieldwork sites & \\
North Wales (site A) & 4 \\
North Wales (site B) & 4 \\
Merseyside (site C) & 3 \\
Merseyside (site D) & 2 \\
Merseyside (site E) & 1 \\
Merseyside (site F) & 2 \\
Greater Manchester (site G) & 4 \\
London (site H) & 5 \\
\hline
\end{tabular}

interviewed. They did not refuse explicitly, but rather failed to attend arranged interviews or cancelled.

We conducted in-depth interviews with 25 consenting adults living in deprived areas (table 1 ) either in a service setting, in their own home or, in one case, in a café. We asked participants to talk about their experiences of public services (such as Sure Start, social services, health services) and living in their neighbourhood. Participants were encouraged to talk about positive as well as negative experiences. Interviews were digitally recorded (with permission) where practicable, otherwise notes were taken. Experiences and views expressed during observations were also recorded in field notes. The study was approved by the Liverpool School of Tropical Medicine research ethics committee.

Line-by-line open coding of the transcripts and field notes was performed whereby segments of text were grouped into categories and subcategories using the constant comparative method. Axial coding was then conducted, using the paradigm model to make sense of relationships between categories. Atlas.ti (Scientific Software Development, Berlin), software for the storage, management, analysis and retrieval of qualitative data, aided this process. The analytical strategy and focus were discussed by all the authors and a consensus reached about the labels for emerging themes, the arrangement of themes into categories and subcategories and the relationships between those categories. We aimed to identify service features that undermine or buffer health and well-being and the conditions in which they arose. Our final interpretations were informed by our analysis of the dataset as a whole (data from interviews with clients and professionals and observational data) and by our reading of the literature. In this paper, we present findings on participants' negative perceptions, specifically the perceived consequences of seeking help and health care. The names of participants have been changed to protect their anonymity.

\section{RESULTS}

A range of factors relating to participants' experiences and perceptions influenced the take-up of services (box 2). Below, we report three interrelated themes that influenced participants' uptake of services with potential consequences for health. These are illustrated using case studies (boxes 3-6). The cases were selected because they each encapsulate several themes and demonstrate the interplay between them, and not because the cases themselves were representative of the sample.

\section{Perceived risks in using services}

The prevailing view amongst participants was that encounters with public services were risky. First, participants expressed concern about the risk of losing resources, e.g. the reduction or

\section{Box 1 Summary of adversities reported by/} observed in sample

\section{Environmental}

Living in a deprived area

Crime and antisocial behaviour

Conflict and tension in the community

Experience of anger/violence

Housing problems

Lack of local facilities and shops

Health related

Poverty

Chronic health problems (e.g. intellectual disability, diabetes,

depression, stroke, hepatitis C, chronic arthritis)

Teenage pregnancy

Feeling worried or stressed

Isolation

Lack of confidence and self-esteem

Lack of self-determination and basic choices

Drug-related problems

Child with attention deficit hyperactivity disorder (ADHD)

Service related

Dependency on welfare benefits

Past/current contact with Social Services

Children taken into care

Conflict with public services, e.g. social services

Poor health care

Poor availability of services

Needs not met by services (e.g. social/interpersonal, educa-

tion, employment, literacy, repairs/substandard housing,

parenting problems, community facilities, health care)

Exclusion from school

Contact with the criminal justice system

withdrawal of social security benefits ( site H). One mother described having to prove to services that her partner gave her food and nappies, not the money for these items, in order to protect her benefit entitlement (Becky).

Second, concern was expressed about the risk of being misunderstood or harshly judged. It was thought that services could take requests for help "the wrong way", that is as an admission of failure to cope that might be used against them, rather than as a reason to provide help and support (site $\mathrm{H}$ ).

\section{Box 2 Summary of factors that influence the take- up of services}

Likelihood of losing resources

Likelihood of losing custody of children

Likelihood of being misunderstood or harshly judged

Likelihood of receiving practical help and support

Likelihood of being listened to and having needs met

Previous negative or positive experience

Quality of services and facilities

Accessibility (location, transport, cost, eligibility criteria, literacy)

Availability of secondary benefits (support from peer group, make and meet friends, someone to talk to, have a laugh, relaxation/break, transferable skills, e.g. communication skills gained from parenting class)

Child care provision

Familiarity with service, friend's recommendation 


\section{Box 3 Case studies}

\section{Alison, single mother of two}

One of Alison's children had been removed into care and she risked losing custody of her other child, which caused her a great deal of anxiety: "If they try to take her off me I would kill myself, I would kill myself, because I couldn't cope, I couldn't do it."

Despite a clear need for support, Alison was simply being monitored, but despite this lack of practical help felt unable to refuse to see social services for fear of losing her daughter:

Every time I ask for something I don't get it, every time I ask for help I don't get it.

[Social Workers] interfering, coming out and telling me what to do, if I don't open the door for them it looks bad on me. They've ruined my life.

Consequently, Alison avoided exposing herself to further uninvited judgements by staying at home, and not using the local Sure Start facilities:

I just don't like to go out on my own. I just don't know who's going to be there when I get there. I just get dead. It's like a panic attack. I just think everyone is going, "oh she's had her kids taken off her, look at her". Because that's what it's like around here everyone is talking about you. If they're not talking about you they're looking at you and it's terrible.

\section{Jane, single mother of a new baby}

Jane was being visited at home by health visitors, midwives and district nurses for a health problem resulting from complications following childbirth. Jane discovered that concerns had been expressed about her mental health, written in her notes and discussed between different agencies:

They wasn't helping, it was just like interfering. I didn't like the implication that I was suffering from postnatal depression and therefore I couldn't look after my baby. [... If [the district nurses] had asked about contacting the health visitor - would you like me to contact the health visitor because I don't think [the baby] looks very well, or I think you appear to have postnatal depression would you like me to contact the health visitor and maybe we can see about ... they didn't do that. No, I wouldn't like to go through all that again. Just people interfering.

Yet despite their concerns and claiming to offer "help and support", Jane did not receive any practical support, such as help with housework:

[I said to the health visitor] "What do you want now? There was a baby clinic on Thursday at the surgery, so why do you want to come to my house? This is ridiculous." She said, "Oh well it's to keep a closer eye on you." I said, "What do you mean?" She said, "Well, considering everything that's happened to you, you might feel grateful for little more help and support." I said, "No, not off [the health visitors] no. You can come round if you want do my washing for me, Hoover up and things. Are you going to Hoover for me? No." They are not going to offer me any practical help, they are just going to sit there and judge me.

Jane became increasingly worried that she was at risk of losing her baby:

Your imagination starts working overtime. [You think] why are they doing this? Before you know it, they are going to take the baby off you. [...] But then I did start thinking ..., even if they did call, whoever, I don't know who, Social Services or whatever, they will see that there's nothing wrong, that he's a perfectly happy healthy baby. And I thought hold on a minute, what if they can't see it? And I thought am I giving them too much credit here? I don't know.

\section{Cathy, married mother of three}

Cathy described how, while pregnant with her third child, her middle child manifested behavioural problems and began having problems at school. She asked for help and support from social services and was pleased when she was offered, amongst other things, a place in an after-school club. The offer was made, however, on condition that she handed over her unborn baby for adoption. Confused, she sought support from a neighbour, refused to agree to the conditions and kept her baby. She did not receive any help from social services.

Participants considered that being in receipt of social security benefits and living on deprived housing estates meant that social welfare workers and others made negative assumptions about them.

Third, parents were particularly wary of social services due to a perceived risk of losing custody of their children. For some, this risk had become a reality with devastating consequences, "If [services] rip you apart they can't stick it back together again" (Brenda). Subsequently participants such as Alison experienced feelings of immense desperation (box 3 ).

Finally, in their encounters with services, participants faced the risk of not receiving practical help or support. Participants reported that there is often "nothing constructive" (Ruby) that services can do to help. One father with a son who got into trouble with the police remarked how services were not preventative, "you have to do something wrong in order to get things like the youth worker" (Dave). Participants' accounts highlighted how little practical support and help seems to be on offer to enable hard-pressed families to manage (box 3 ).

\section{Rise in surveillance}

Participants were increasingly aware of the expansion of surveillance in place of practical support, particularly in the disadvantaged communities where they lived. Some described living in fear of "being told on", for example for cheating the benefits system ( site $\mathrm{H}$ ). Parents acutely felt such surveillance (box 4). Some surmised that the registration of families by their local Sure Start was simply about gathering information, especially as no services seemed to follow (site G). One mother commented that, "It's difficult to [discipline children] because schools and parents are constantly watched and could be accused of abuse or neglect" (Georgette). Participants described 


\section{Box 4 Case studies}

Diane, mother of one and former drug user

Diane and her partner were subject to constant interference by social services, neighbours, school and police, and faced repeated allegations and investigations of neglect and risks to their son. Significantly, none of the allegations was substantiated. Diane described how social workers were "looking down on us". She said that her son would go out looking OK, but at the end of the day, like a normal kid, would be untidy, and that would always be when the social worker came. She said that her son would be bathed every night, his uniform would be washed and pressed and he would be on time for school, he would go swimming, and she said she always "made sure I was presentable" for his sake.

Julie, mother and former "looked after" child Julie said that she didn't have "anything good" to say about social services because she had been in care as a child. She thought that this made her open to observation by social services and this was "the problem with social services":

Just because I'd been in care, they come checking up on my kids.

Julie felt that contact with social services was unavoidable:

You don't need to go to them because they're always interfering in your life anyway [...] they try to tell you how to run your life and how to bring up your kids.

encounters with welfare professionals who had information about them from other agencies, for example Sure Start staff revealing information which could only have been sourced from the Social Services department or community nurses (site G). Other participants expressed fear about confidentiality being broken and not having any power to do anything about it (site $\mathrm{H}$ ). Although none of the participants described being referred to social services by Sure Start, several Sure Start workers admitted doing so.

Participants' wariness of social services pervaded their perceptions of all public services, including health, because of the perceived risk of being referred to social services. Also, neighbours had referred some participants to social services, and family social workers confirmed that referrals from neighbours were quite common. Participants understood that this aspect of their social and physical location was intensifying and inescapable.

\section{Adverse consequences}

\section{Coping by avoiding services}

Participants generally indicated a deep-seated distrust of and disappointment with public services, especially social services, leading to the view: "avoid them in your life at all costs" (Tina). Where participants perceived public services as risky and surveillance as omnipresent, this affected their willingness to use public spaces and, consequently, their use of all kinds of services. Contact with services was often a last resort in desperate circumstances or uninvited (box 4). Residents of a deprived estate avoided contacting housing services about repairs and other issues because they were treated badly by staff and repairs went undone (site B). Participants with learning disabilities avoided using social services day centres because they were treated disrespectfully and their needs went unmet (site F). We found evidence of participants avoiding taking their children for health checks (box 5) and avoiding Sure Start premises and other public places (box 1), because these were perceived to be places where they could be negatively judged or referred to social services by neighbours or professionals.
Isolation and anxiety

As a consequence of their perceptions and their resulting avoidance behaviour, participants experienced isolation: not being able to "mix" with people socially and having "no-one to go to" (Brenda; box 5). Participants' accounts reveal anxiety arising from the risks they associated with services and the expansion of surveillance. Parents expressed anxiety about their children's behaviour in public places and about appearing to be neglectful of children (box 4). All participants carried the burden of having to give the right impression to services: about their income, their ability to cope, their capacity as parents, their children's behaviour. Participants believed that it was unfair to have to live with this constant anxiety ( site $\mathrm{H}$ ).

\section{DISCUSSION}

Qualitative research has identified financial, social and cultural factors to account for families' inhibited use of preventative and potentially supportive services. ${ }^{319}$ The perception of risk, including the risk of stigmatisation, negative judgement and inadequate help presented by encounters with potentially beneficial public services has been found to affect help-seeking behaviour across a variety of patient groups. ${ }^{20-23}$ For the participants in this study, public services were generally perceived not as beneficial, but as a source of distrust and a potential risk to well-being. Approaching services was akin to taking a gamble that might or might not result in their needs being met. Faced with this "choice", participants employed strategies to minimise the risks to themselves and their families that on the surface may appear risky to health.

It is important to note that the accounts analysed in this paper relate to the interviewees' perceptions of the risks of using services and their perceptions of seeking help and health care. We cannot draw conclusions from these accounts about the motives or intentions of the professionals towards their clients in the reported encounters. What the study can do, however, is to report what the consequences of those perceptions were for the disadvantaged families concerned.

\section{Implications for health and well-being}

Two aspects of our findings have implications for health. First, the constant maintenance of outward appearances placed participants under considerable stress and strain. In addition, using public services and spaces generated anxiety.

Second, avoiding public services and spaces had direct and indirect consequences for the health of disadvantaged families. In some cases, access to preventative health services and other social interventions was affected as participants avoided children's health screening, immunisations and Sure Start. Our findings alerted us to the possibility that families may turn to the accident and emergency department in times of crisis instead of using primary care services, which in the event means that they miss out on preventative services and early interventions. Participants who sought to avoid exposure to the perceived risks were instead exposed to the potentially health-damaging consequences of isolation and the loss of support mechanisms - support that might otherwise encourage their take-up of services.

Despite the health-damaging potential of their actions, the strategies reported here represent participants' best attempts to sustain their families' stability and well-being. Health-damaging strategies, such as feeding children sweets, early weaning and smoking, have been shown elsewhere to offer temporary resolution of the conflict between the demands of parenting and the constraints of poverty. ${ }^{19}{ }^{24}$ Studies of mothers' experiences of child immunisation have found that mothers deferred or defaulted on future visits following adverse experiences of immunisation, including emotional distress, non-empathic treatment by doctors and being judged. ${ }^{325-27}$ In 
Box 5 Case studies

Ruby, married mother of six and grandmother

Ruby asked social services to place her (then) teenage daughter on a temporary care order as a last resort. Ruby was dissatisfied with child and family services and the family therapy provided by a psychologist. Her daughter was placed in a secure unit after running away from the children's home. Ruby reflected that approaching services made things worse:

I thought well I want my child back, she's in a worse situation now. That's not what I wanted. I wanted help.

Following this experience, Ruby's daughter was reluctant to engage with services when she later ran into difficulties as a mother of four: [My daughter] didn't have much faith in statutory agencies [...] anybody from a statutory agency was greeted with fear. Fear of being condemned and told that she was doing it wrong and looked down upon, as a young mum. She felt very intimidated and that they were trying to take control.

[My daughter] had the fire [...] A week after that she had a robbery and the TV and the video and everything went, and that's when social services come. She went for a loan to DSS [Department of Social Security] and they said, "you can't have any more money". [...] She was living on $£ 165$ a week [...] no wonder she was living in poverty, [...] and things had just got worse and worse and worse and she was in such a mess. [...] She didn't have a partner, you know, I wasn't there, there was no family at all, no support network. [...] to protect herself she isolated herself, the kids stopped going to school. She didn't go out, she didn't even go shopping, she'd get her mate to do it because she was that frightened of her kids being removed.

Desperate circumstances eventually forced her daughter to approach services:

If [the kids] had an accident she took them straight to $A$ \& E. Over the fire they went straight to $A \& E$. When they were getting injections in case their lungs were damaged with smoke, she picked them up and took them out because they were screaming. They hadn't had sickle cell tests which they had to have. [...] [My grandson] needed teeth out and the hospital wouldn't do it because there was no record of him having the sickle cell test. [My daughter] couldn't cope with children crying when they were having these kinds of treatments.

Both Ruby and her daughter had been reported by a neighbour to social services.

\section{Tina, single mother of four}

Tina felt judged when she took her baby to be weighed. She feared that she was suspected of harming her son and stopped taking him to the clinic, inviting further judgement:

We went up to get him weighed one day and they had a little [picture] of the baby and it had circles on the body of the baby and I said, "What's that?" And they said, "They are bruises and this is last week's and do you want to explain why there are bruises?" [I said,] "I have already explained to the Health Visitor that he's climbing." But [they said] "He's only 8 months old he can't possibly be climbing." But I said, "But he is, you know", and I said, "Why would you suspect that I would hurt him? I had two more before him. Why all of a sudden would I start?" So I stopped going to get him weighed. Then he had a stomach bug and I brought him into hospital and they said, "Why haven't you been taking him to get weighed?" And I explained the situation. [...] [I got] all funny looks from the doctors and everybody.

Tina expressed concern that, "If they take him off me then they are going to take the other two [children] off me". She described the feelings of isolation resulting from this suspicion:

It made me cut off, because as a result of that particular accusation [my son] never got weighed again. [...] So it's fear and rejection then, [...] And isolated, you feel really isolated within the community, because nobody likes you, because your child behaves in a certain way, therefore that's a direct response to you as a person so therefore you are a bad person as well as a bad mother.

Couldn't anybody have spoken of the other two, they're good!

our study, participants felt powerlessness to resist what they perceived to be the damaging judgements and interventions of public services. From their perspective, they acted responsibly by taking actions that professionals might deem irresponsible.

\section{Implications for offering genuinely supportive services} Our analysis highlights the pitfalls that must be avoided if the proposed intensive identification and intervention policies are to be viewed by disadvantaged families as helpful rather than threatening. The question posed by participants - Can I risk using public services? - reflects how the surveillance functions of health and welfare services have expanded in place of practical support over the past 15 years. ${ }^{28}{ }^{29}$ Families living in poverty and adverse conditions are disproportionately subject to surveillance by services: they encounter multiple public services, are over-represented amongst social services clients and are increasingly the focus of government initiatives. ${ }^{30}$ Our findings suggest that neighbours telling on one another could have potentially damaging, socially divisive, consequences for already fragile communities. Coupled with the demise of preventative and practical support, services in the most disadvantaged communities are more likely to be stigmatising and alienating, and families who have the most to gain are least likely to seek help. ${ }^{20}{ }^{31}$ Interventions that mediate access to welfare services while minimising exposure to stigma are of potential utility. ${ }^{32}$ Nevertheless, our findings suggest that even services that endeavour not to be stigmatising are at risk of "contamination" where families are aware that information is shared between agencies, extending the range of places that they consider risky.

If public services are to succeed in providing support to the most disadvantaged families, greater efforts need to go into building trust and demonstrating understanding for the strategies these families use to maintain their well-being against formidable odds. 


\section{What is already known on this subject}

The low uptake of preventative services in disadvantaged communities is an ongoing challenge for public health.

A UK government initiative on poverty and social exclusion aims to provide extra support to the most disadvantaged families, to intervene at an early stage to prevent social problems later on.

Not enough is known about how to provide such supportive services without stigmatising or alienating the people they are intended to help.

\section{What this study adds}

Interviews with families in poverty revealed that encounters with public services were perceived to be associated with the risk of losing resources, being misunderstood or harshly judged or, ultimately, losing their children.

Participants perceived that they were subject to high, and increasing, levels of surveillance, with fear of "being told on" by neighbours, in addition to service providers, adding to anxiety.

Adverse consequences of perceived risks and surveillance included avoiding child health and social services, anxiety and self-imposed isolation.

The study highlighted piffalls that need to be avoided when designing genuinely supportive services for the most marginalised communities.

\section{Policy implications}

Health and welfare services in England have expanded their surveillance functions, while reducing practical and preventative support.

This leads to a growing tendency for services in the most disadvantaged communities to be stigmatising and alienating, discouraging the families most in need of help.

Even services that endeavour not to be stigmatising are at risk of "contamination" as families are aware that information is shared between agencies, extending the range of places that they consider risky.

If public services are to succeed in providing support to the most disadvantaged families, greater effort needs to go into building trust and demonstrating understanding for the strategies these families use to maintain their well-being against formidable odds.

\section{ACKNOWLEDGEMENTS}

We would like to thank the people who participated in this study.

\section{Authors' affiliations}

Krysia Canvin, Margaret Whitehead, Division of Public Health, University of Liverpool, Whelan Building, Quadrangle, Brownlow Hill, Liverpool L69 3GB, UK

Chris Jones, Department of Sociology and Social Policy, University of Liverpool, Eleanor Rathbone Building, Bedford Street South, Liverpool L69 7ZA, UK

Anneli Marttila, Bo Burström, Department of Public Health Sciences, Karolinska Institutet, Norrbacka, SE-171 76 Stockholm, Sweden

Funding: The authors are funded by the British Economic and Social Research Council (ESRC) under Grant No. L326253061 to study how social welfare policies and practices build or undermine resilience in poor households in Britain and Sweden, as part of the multi-project ESRC Priority
Network on Human Capability and Resilience (www.ucl.ac.uk/humancapabilityandresilience). The funders of this study had no role in its design, conduct, analysis or interpretation. The ESRC bears no responsibility for the analyses or interpretations presented here.

Competing interests: None.

\section{REFERENCES}

1 Acheson D. Independent inquiry into inequalities in health report. London: Stationery Office, 1998

2 Samad L, Tate AR, Dezateux C, et al. Differences in risk factors for partial and no immunisation in the first year of life: prospective cohort study. BMJ 2006:332:1312-13

3 Harrington PM, Woodman C, Shannon WF. Low immunisation uptake: Is the process the problem? J Epidemiol Community Health 2000;54:394-400.

4 Wiggins M, Oakley A, Roberts I, et al. Postnatal support for mothers living in disadvantaged inner city areas: a randomised controlled trial. J Epidemiol Community Health 2005;59:288-95

5 Woods L, Rachet B, Riga M, et al. Geographical variation in life expectancy at birth in England and Wales is largely explained by deprivation. J Epidemiol Community Health 2005;59:115-20.

6 Doran T, Drever F, Whitehead M. Health under- and over-achievement in English local authorities. J Epidemiol Community Health 2006;60:686-93.

7 Cummins S, Stafford M, Macintyre S, et al. Neighbourhood environment and its association with self-rated health: evidence from Scotland and England. $J$ Epidemiol Community Health 2005;59:207-13.

8 Hart J. Three decades of the inverse care law. BMJ 2000;320:18-19.

9 Pell J, Pell A, Norrie J, et al. Effect of socioeconomic deprivation on waiting time for cardiac surgery: retrospective cohort study. BMJ 2000;320:15-18.

10 Fraser S, Bunce C, Wormald R, et al. Deprivation and late presentation of glaucoma: case-control study. BMJ 2001;322:639-43.

11 Blair T. Our sovereign values, fairness. 5 September 2006. http://www.number10.gov.uk/output/Page10037.asp (accessed 13 October 2006).

12 Cabinet Office. Reaching out: an action plan on social exclusion. London: HM Government, 2006.

13 Wood D, ed. A Report on the Surveillance Society. For the Information Commissioner. Presented to the 28th International Data Protection and Privacy Commissioners' Conference, 1-2 November 2006. Newcastle: Surveillance Studies Network, 2006, http://www.ico.gov.uk/upload/documents/library/ data_protection/practical_application/surveillance_society_full_report_ 2006.pdf (accessed 21 November 2006).

14 Joseph Rowntree Foundation Press Release. Welcome for PM's new social exclusion initiative comes with warning to avoid stigma. 5 September 2006. http:// www.jif.org.uk/pressroom/releases/050906.asp (accessed 13 October 2006).

15 Abrahams C. NCH's response to Every Child Matters. 2004. http://www.nch.org uk/information/index.php?i= 118 (accessed 21 September 2006).

16 Dowty T. What type of help families need and what help is available now? Presented to the LSE Department of Social Policy workshop on tracking children: a road to danger in the Children Bill. LSE 6 April 2004. http://trackingchildren.Ise.ac.uk/dowty.pdf (accessed 21 September 2006).

17 Penna S. The Children Act 2004: Child protection and social surveillance. J Social Welf Fam Law 2005;27:143-57.

18 Strauss A, Corbin J. Basics of qualitative research. London: Sage, 1990

19 Graham H. Hardship and health in women's lives. London: Harvester Wheatsheaf, 1993.

20 Attree P. Parenting support in the context of poverty: a meta-synthesis of the qualitative evidence. Health Soc Care Community 2005;13:330-7.

21 Hunt K, Emslie C, Watt G. Lay constructions of a family history of heart disease: potential for misunderstandings in the clinical encounter? Lancet 2001;357:1 168-71

22 Horrocks S, Somerset M, Stoddart H, et al. What prevents older people from seeking treatment for urinary incontinence? A qualitative exploration of barriers to the use of community continence services. Fam Pract 2004;21:689-96.

23 Power $\mathbf{E}$. The unfreedom of being other: Canadian lone mothers' experiences of poverty and 'life on the cheque'. Sociology 2005;39:643-60.

24 Graham H. Researching women's health work: a study of the lifestyles of mothers on income support. In: Bywaters P, McLeod E, eds. Working for equality in health. London: Routledge, 1996:161-78.

25 Bennett $\mathbf{P}$, Smith C. Parents' attitudinal and social influences on childhood vaccination. Health Educ Res 1992;7:341-8.

26 Coreil J, Augustin A, Halsey NA, et al. Social and psychological costs of preventive child health services in Haiti. Soc Sci Med 1994:38:231-8.

27 Houseman C, Butterfoss FD, Morrow AL, et al. Focus groups among public, military and private sector mothers: insights to improve the immunization process. Public Health Nurs 1997; 14:235-43.

28 Armstrong D. The rise of surveillance medicine. Sociol Health IIIn 1995; 17:393-404.

29 Cowley S, Mitcheson J, Houston AM. Structuring health needs assessments: the medicalisation of health visiting. Sociol Health Illn 2004;26:503-26.

30 Belsky J, Melhuish E, Barnes J, the National Evaluation of Sure Start Research Team, et al. Effects of Sure Start local programmes on children and families: early findings from a quasi-experimental, cross sectional study. BMJ 2006;332:1476-8.

31 Jones C, Novak T. Poverty, welfare and the disciplinary state. London: Routledge, 1999

32 Graham H, McDermott E. Qualitative research and the evidence base of policy: insights from studies of teenage mothers in the UK. J Soc Policy 2005;35:21-37. 